\title{
Power-3 Heronian Mean Labeling of Graphs
}

\author{
M.Kaaviya Shree, K.Sharmilaa
}

Abstract: Let $G=(V, E)$ be an undirected graph having a vertices and $b$ edges. Now, defining a function say, $\beta: V(G) \rightarrow$ $\{1,2,3, \ldots, b+1\}$ is called Power-3 Heronian Mean Labeling of a graph $G$ if we could able to label the vertices $x \in V$ with dissimilar elements from $1,2, \ldots, b+1$ such that it induces an edge labeling $\beta^{*}: E(G) \rightarrow\{1,2,3, \ldots, b\}$ defined as,

$$
\beta^{*}(e=u v)=\left\lfloor\sqrt[3]{\frac{\beta(u)^{3}+(\beta(u) \beta(v))^{\frac{3}{2}}+\beta(v)^{3}}{3}}\right\rfloor,
$$

is dissimilar for all the edges $e=u v \in E$. (i,e.) It intimates that the dissimilar vertex labeling induces a dissimilar edge labeling on the graph. The graph which owns Power-3 Heronian Mean Labeling is called an Power-3 Heronian Mean Graph. In this, we have advocated the Power-3 Heronian Mean Labeling of some standard graphs like Path, Comb, Caterpillar, Triangular Snake, Quadrilateral Snake and Ladder.

Keywords : Power-3 Heronian Mean Labeling, Power-3 Heronian Mean Graph, Path, Comb, Caterpillar, Triangular Snake, Quadrilateral Snake and Ladder.

\section{INTRODUCTION}

The graph $G$ we considered here are simple, finite and undirected graphs. $V(G)$ and $E(G)$ represents the vertex set and the edge set of a graph $G$. For graph theoretic terminology, we refer to Harary.F [2] and Gallian.J.A [1]. The notion of Mean Labeling of graphs was introduced by Somasundaram.S and Ponraj [3] in 2003. Sandhya.S.S, Ebin Raja Merly.E and Deepa.S.D [4] introduced the notion of Heronian Mean Labeling of graphs in 2017. On the same lines we define and study Power-3 Heronian Mean Labeling of graphs.

\section{BASIC DEFINITIONS}

The upcoming basic definitions are needed for the current study.

\section{A. Definition}

Generally, Path is represented by a walk having dissimilar vertices. A Path is represented by $P_{n}$. The Path $P_{n}$ has $n$ vertices and $n-1$ edges.

\section{B. Definition}

Comb is attained by attaching a complete graph $K_{1}$ to

Revised Manuscript Received on April 25, 2020.

* Correspondence Author

M.Kaaviya Shree*, Department of Mathematics (PG), PSGR Krishnammal College for Women, Coimbatore, Tamilnadu, India.

K.Sharmilaa, Department of Mathematics (PG), PSGR Krishnammal College for Women, Coimbatore, Tamilnadu, India.

(C) The Authors. Published by Blue Eyes Intelligence Engineering and Sciences Publication (BEIESP). This is an open access article under the CC BY-NC-ND license (http://creativecommons.org/licenses/by-nc-nd/4.0/) each vertex of a path. Generally, it gas $2 n$ vertices and $2 n-1$ edges.

\section{Definition}

Caterpillar is attained by removing the pendant vertices of a path from the tree. It has $3 n$ vertices and $3 n-1$ edges.

\section{Definition}

A Triangular Snake $\boldsymbol{T}_{\boldsymbol{m}}$ is attained by attaching every pair of vertices of a path to another new vertex. (i,e.,) we can replace each edge of a path $P_{n}$ by a cyclic graph $C_{3}$. Generally, it has $2 n+1$ vertices and $3 n$ edges.

\section{E. Definition}

A Quadrilateral Snake $\boldsymbol{Q}_{\boldsymbol{m}}$ is attained by attaching every pair of vertices of a path to another two new vertices. (i,e.,) we can replace each edge of a path $P_{n}$ by a cyclic graph $C_{4}$. Generally, it has $3 n-2$ vertices and $4 n-4$ edges.

\section{F. Definition}

The Ladder $\boldsymbol{L}_{\boldsymbol{n}}$ is the product graph $P_{2} \times P_{n} . L_{n}$ has $2 n$ vertices and $3 n-2$ edges.

\section{MAIN RESULTS}

\section{Theorem: 1}

For every $n$, Path $P_{n}$ is said to be a Power-3 Heronian Mean graph.

Proof:

Let us consider a Path $P_{n}$ having the vertices $u_{1}, u_{2}, u_{3}, \ldots, u_{n}$ of length $n$. Generally, the gragh $P_{n}$ have $n$ vertices and $n-1$ edges.

Now, defining a function $\beta: V\left(P_{n}\right) \rightarrow\{1,2,3, \ldots, b+1\}$ by

$$
\beta\left(u_{i}\right)=i \quad \text {, where } i=1,2, \ldots, n
$$

Then the induced edge labels are given by,

$$
\beta^{*}\left(u_{i} u_{i+1}\right)=i \quad \text {, where } i=1,2, \ldots, n-1
$$

Then we attain a dissimilar value for the edges.

Therefore, $P_{n}$ is said to be a Power-3 Heronian Mean graph.

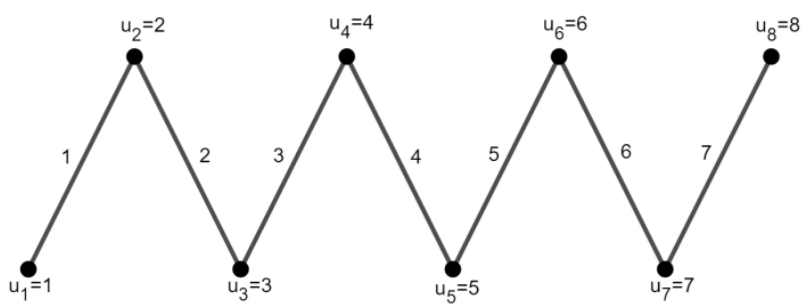

Figure 1: $\boldsymbol{P}_{\mathbf{8}}$

\section{Theorem: 2}

For every $n$, Comb $P_{n} \odot K_{1}$ is said to be a Power-3 Heronian Mean graph.

Proof:

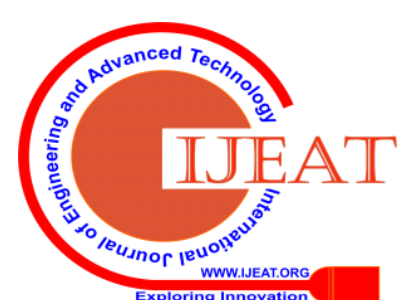




\section{Power-3 Heronian Mean Labeling of Graphs}

Let $P_{n} \odot \mathrm{K}_{1}$ be a comb attained by attaching a complete graph $K_{1}$ to each vertex of $P_{n}$. Generally, it has $2 n$ vertices and $2 n-1$ edges.

Now, defining a function $\beta: V(G) \rightarrow\{1,2,3, \ldots, b+1\}$ by

$$
\begin{aligned}
& \beta\left(u_{i}\right)=\left\{\begin{array}{cl}
2 i & , \text { where } i=1 \\
2 i-1 & , \text { where } i=2,3, \ldots, n
\end{array}\right. \\
& \beta\left(v_{i}\right)=\left\{\begin{array}{cl}
i & , \text { where } i=1 \\
2 i & \text {, where } i=2,3, \ldots, n
\end{array}\right.
\end{aligned}
$$

Then the induced edge labels are,

$$
\begin{array}{ll}
\beta^{*}\left(u_{i} u_{i+1}\right)=2 i & , \text { where } i=1,2, \ldots, n-1 \\
\beta^{*}\left(u_{i} v_{i}\right)=2 i-1 & \text {, where } i=1,2, \ldots, n
\end{array}
$$

Then we attain a dissimilar value for the edges.

Therefore, $P_{n} \odot \mathrm{K}_{1}$ is said to be a Power-3 Heronian Mean graph.

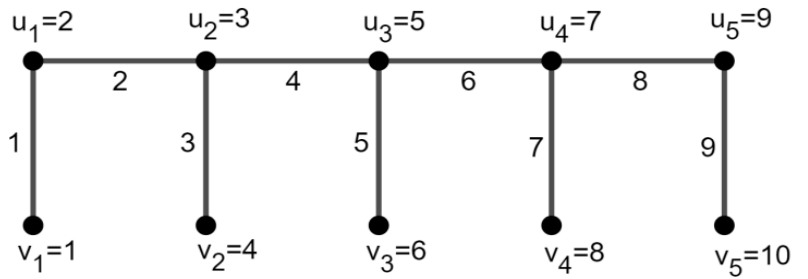

Figure 2: $\boldsymbol{P}_{\mathbf{5}} \odot \mathbf{K}_{\mathbf{1}}$

\section{Theorem: 3}

Assume $G$ be a graph attained by joining a single edge to the two sides of each vertex of $P_{n}$. Then, $G$ is said to be a Power-3 Heronian Mean graph.

\section{Proof:}

Assume $G$ be a graph attained by joining a single edge to the two sides of each vertex of $\mathrm{P}_{\mathrm{n}}$. Let $P_{n}$ be a path $v_{1}, v_{2}, v_{3}, \ldots, v_{n}$. Let $u_{i}$ and $w_{i}$ be the pendant vertices adjacent to $v_{i}$. Generally, it has $3 n$ vertices and $3 n-1$ edges.

Now, defining a function $\beta: V(G) \rightarrow\{1,2,3, \ldots, b+1\}$ by

$$
\begin{array}{ll}
\beta\left(u_{i}\right)=3 i-2 & , \text { where } i=1,2, \ldots, n \\
\beta\left(v_{i}\right)=3 i-1 & \text {, where } i=1,2, \ldots, n \\
\beta\left(w_{i}\right)=3 i & \text {, where } i=1,2, \ldots, n
\end{array}
$$

Then the induced edge labels are given by,

$$
\begin{array}{cc}
\beta^{*}\left(v_{i} v_{i+1}\right)=3 i & , \text { where } i=1,2, \ldots,(n-1) \\
\beta^{*}\left(v_{i} u_{i}\right)=3 i-2 & , \text { where } i=1,2, \ldots, n \\
\beta^{*}\left(v_{i} w_{i}\right)=3 i-1 & \text {, where } i=1,2, \ldots, n
\end{array}
$$

Then we attain a dissimilar value for the edges.

Therefore, $G$ is said to be a Power-3 Heronian Mean graph.

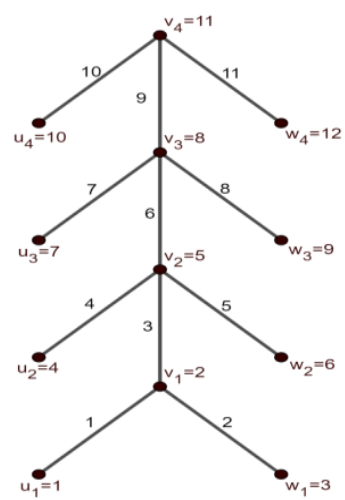

Figure 3: Caterpillar

\section{Theorem: 4}

Triangular Snake $T_{m}$ is said to be a Power-3 Heronian
Mean graph.

\section{Proof:}

Assume $\mathrm{T}_{\mathrm{m}}$ be a Triangular Snake. It is attained by attaching every pair of vertices of a path to another new vertex say $\mathrm{v}_{i}$. (i,e.,) we can replace each edge of a $P_{n}$ by a cyclic graph $C_{3}$. Generally, it has $2 n+1$ vertices and $3 n$ edges.

Now, defining a function $\beta: V(G) \rightarrow\{1,2,3, \ldots, b+1\}$ by

$$
\begin{array}{ll}
\beta\left(u_{i}\right)=3 i-2 & , \text { where } i=1,2, \ldots, n \\
\beta\left(v_{i}\right)=3 i-1 & \text {, where } i=1,2, \ldots, n
\end{array}
$$

Then the induced edge labels are given by,

$$
\begin{array}{cl}
\beta^{*}\left(u_{i} u_{i+1}\right)=3 i-1 & , \text { where } i=1,2, \ldots,(n-1) \\
\beta^{*}\left(u_{i} v_{i}\right)=3 i-2 & \text {, where } i=1,2, \ldots,(n-1) \\
\beta^{*}\left(u_{i+1} v_{i}\right)=3 i & \text {, where } i=1,2, \ldots,(n-1)
\end{array}
$$

Then we attain a dissimilar value for the edges.

Therefore, $T_{m}$ is said to be a Power-3 Heronian Mean graph.

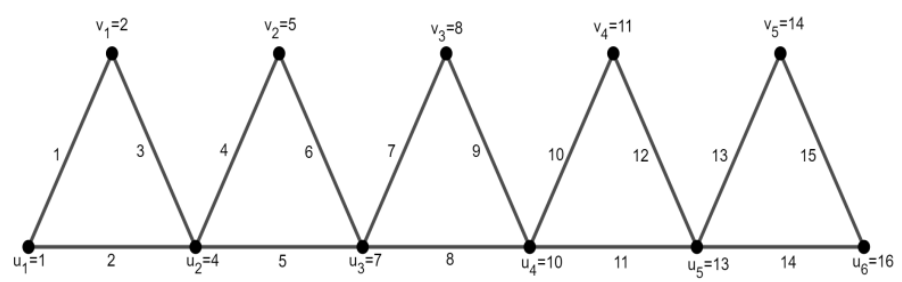

Figure 4: $\boldsymbol{T}_{5}$

\section{Theorem: 5}

Quadrilateral Snake $Q_{m}$ is said to be a Power-3 Heronian Mean graph.

\section{Proof:}

Assume $Q_{m}$ be a Quadrilateral Snake. It is attained by attaching every pair of vertices of a path to another two new vertices say $\mathrm{v}_{i}$ and $\mathrm{w}_{i}$. (i,e.,) we can replace each edge of a $P_{n}$ by a cyclic graph $C_{4}$. Generally, it has $3 n-2$ vertices and $4 n-4$ edges.

Now, defining a function $\beta: V(G) \rightarrow\{1,2,3, \ldots, b+1\}$ by

$$
\begin{array}{ll}
\beta\left(u_{i}\right)=4 i-3 & , \text { where } i=1,2, \ldots, n \\
\beta\left(v_{i}\right)=4 i-2 & \text {, where } i=1,2, \ldots, n \\
\beta\left(w_{i}\right)=4 i-1 & \text {, where } i=1,2, \ldots, n
\end{array}
$$

Then the induced edge labels are given by,

$$
\begin{array}{cl}
\beta^{*}\left(u_{i} u_{i+1}\right)=4 i-1 & , \text { where } i=1,2, \ldots,(n-1) \\
\beta^{*}\left(u_{i} v_{i}\right)=4 i-3 & \text {, where } i=1,2, \ldots,(n-1) \\
\beta^{*}\left(u_{i+1} v_{i}\right)=4 i & \text {, where } i=1,2, \ldots,(n-1) \\
\beta^{*}\left(v_{i} w_{i}\right)=4 i-2 & \text {, where } i=1,2, \ldots,(n-1)
\end{array}
$$

Then we attain a dissimilar value for the edges.

Therefore, $Q_{m}$ is said to be a Power-3 Heronian Mean graph.

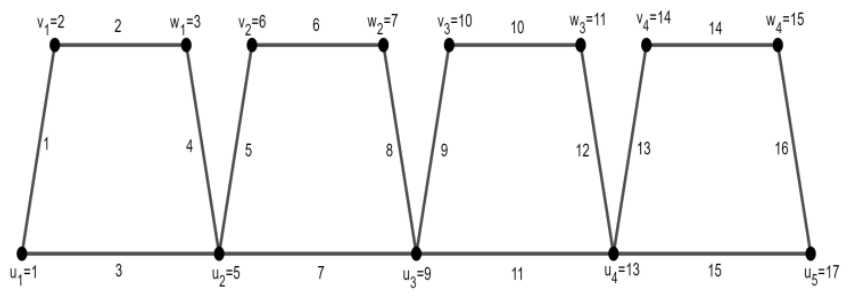

Figure 5: $\boldsymbol{Q}_{4}$

\section{Theorem: 6}

Ladder $L_{n}$ is said to be a Power-3 Heronian Mean graph.

Proof:

\section{Published By:}

Blue Eyes Intelligence Engineering

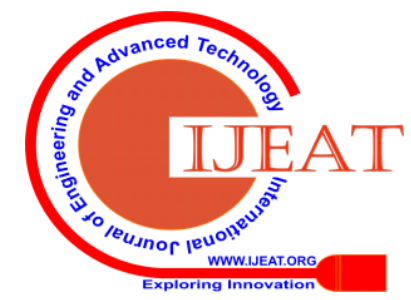


Assume $L_{n}$ denote a Ladder graph. Let $u_{1}, u_{2}, \ldots, u_{n}$ and $v_{1}, v_{2}, \ldots, v_{n}$ be the vertices of two paths having length $n$ in the graph $L_{n}$. Join $u_{i}, v_{i}$. Generally, it has $2 n$ vertices and $3 n-2$ edges.

Now, defining a function $\beta: V(G) \rightarrow\{1,2,3, \ldots, b+1\}$ by

$$
\begin{aligned}
& \beta\left(u_{i}\right)= \begin{cases}3 i-2 & \text {, if } i=1,3,5, \ldots, n \\
3 i-3 & \text {, if } i=2,4,6, \ldots, n\end{cases} \\
& \beta\left(v_{i}\right)=3 i-1 \quad \text {, where } i=1,2, \ldots, n
\end{aligned}
$$

Then the induced edge labels are,

$$
\begin{array}{cl}
\beta^{*}\left(u_{i} u_{i+1}\right)=3 i-1 & , \text { where } i=1,2, \ldots,(n-1) \\
\beta^{*}\left(u_{i} v_{i}\right)=3 i-2 & \text {, where } i=1,2, \ldots,(n-1) \\
\beta^{*}\left(v_{i} v_{i+1}\right)=3 i & \text {, where } i=1,2, \ldots,(n-1)
\end{array}
$$

Then we attain a dissimilar value for the edges.

Therefore, $L_{m}$ is said to be a Power-3 Heronian Mean graph.

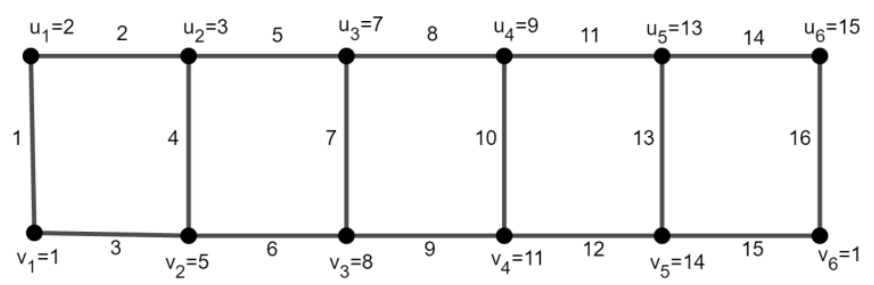

Figure 6: $P_{6} \times P_{2}$

\section{CONCLUSION}

In this paper, we had introduced the notion of Power-3 Heronian Mean Labeling and studied for some standard graphs.

\section{REFERENCES}

1. Gallian.J.A, “A Dynamic Survey of Graph Labeling”, The Electronic Journal of combinatorics (2013).

2. Harary.F, Graph Theory, Narosa publishing House, New Delhi.

3. Ponraj.R and Somasundaram.S, "Mean Labeling of graphs," in National Academy of Science Letters, vol.26, pp.210-213, 2003.

4. Sandhya.S.S, Ebin Raja Merly.E and Deepa.S.D, "Heronian Mean Labeling of Graphs,” International Journal of Mathematics Forum, ISSN 1312-7594, Vol.12, No.15 (2017), pp 705-713.

5. Kaaviya Shree.M and Sharmilaa.K, "Minkowski-4 Mean Labeling of Graphs," International Journal of Mathematics Trends and Technology, volume 66, Issue 3-March 2020, pp 114-118.

\section{AUTHORS PROFILE}

Ms.M.Kaaviya Shree received her B.Sc degree in Mathematics under Bharathiar Unversity, Coimbatore. Currently, she is pursuing her post graduate at PSGR Krishnammal College for Women, Coimbatore. She is also undergoing her research work in Applied Mathematics. She has presented papers in National and International conferences and also published papers in the International journals. Her current research area includes Topology and Graph Theory.

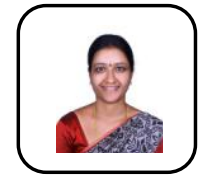

Mrs.K.Sharmilaa received her B.Sc, M.Sc, M.Phill and (Ph.D) in Mathematics. She has 12 years of teaching experience and she is currently working as an Assistant Professor in the Department of Mathematics at PSGR Krishnammal College for Women, Coimbatore. She has published and presented papers in National and International conferences and journals. Her area of interest includes Fluid Dynamics, Graph Theory and Topology. 